\title{
ROLE OF PUBLIC GREEN SPACE IN IMPROVEMENT OF HEALTH IN RESIDENTIAL AREAS
}

\author{
Sheida Korjani \\ Department of Architecture, Tabriz Branch, Islamic Azad University, Tabriz, Iran; \\ *Corresponding author Sheida Korjani, e-mail: sheyda.korjani@gmail.com; \\ Received March, 2018; Accepted April, 2018; Published May, 2018; \\ doi: https://doi.org/10.31407/ijees8312 \\ UOI license: http://u-o-i.org/1.01/ijees/06954466
}

\begin{abstract}
With increasing global interest in creating healthy urban communities, most part of research in urban planning and public health has been progressing on this subject. While discussions and studies in Iran are beginning significant to occur at the macro level, most studies hitherto have centered round public health, with very few considerations to the role of public green spaces. This paper aimed to explore how individual characteristics and public green spaces in the urban community are correlated to the health level in cities, focusing on Iran. This study established a conceptual model to examine the relationship between public health in urban areas, individual attributes, and public green spaces and analyzed the effect of characteristics of public green space on health level using a multilevel regression model. The results revealed that, with the exception of some variables, the correlations between individual health of citizens and public green space variables are statistically significant.
\end{abstract}

Keywords: public green space; community; design; health. 